\title{
Impact of gender and age on inner diameter of arteries forming circle of Willis assessed by multidetector CT.
}

\author{
Prakash Sharma $^{1}$, Subita Lalchan², Subhash KC ${ }^{2}$, Merina Gyawali ${ }^{2}$, Niraj Kushwaha ${ }^{3}$ \\ ${ }^{1}$ Associate Professor, ${ }^{2}$ Assistant Professor, ${ }^{3}$ Resident, department of Radiology, Manipal College of Medical Sciences, Pokhara, \\ Nepal.
}

Received: January 15, 2021

Accepted: February 20, 2021

Published: March 30, 2021

\section{Cite this paper:}

Sharma P, Lalchan S, KC S, Gyawali M, Kushwaha N. Impact of gender and age on inner diameter of arteries forming circle of Willis assessed by multidetector CT. Journal of Brain and Spine Foundation Nepal. 2021:2(1):37-41.

\section{Correspondence:}

Prakash Sharma

Associate Professor

Department of radiology

Manipal College of Medical Sciences, Pokhara, Nepal.

Email: prakashshrm@yahoo.com

ORCID: http://orcid.org/0000-0001-6917-7750

\begin{abstract}
:
Introduction: The circle of Willis (CoW), which is located at the base of the brain is the most important anastomosis between the internal carotid and vertebral system. It is the main distributor of blood to the brain.

Methods: CT head and CT angiography were performed using standard scan parameters. Only the tests with normal radiological reports and appropriate technical standards were included in the study. Component of circle of Willis: Anterior cerebral artery (ACA), Middle cerebral artery (MCA), Anterior communicating artery (Acom), Posterior Communicating artery (PCom), Basilar artery (BA) and Posterior cerebral artery (PCA) were identified and their internal diameter were measured.

Results: Basilar artery was the artery with largest internal diameter with mean diameter of $2.5 \pm 0.52 \mathrm{~mm}$. Men had significantly larger arterial sizes than women in all of the intracranial arteries examined except right PCom, Left PCom and right MCA. Right ACA had significantly larger internal diameter in $<40$ years' age group. BA, left PCA, Bilateral PCom and MCA showed larger diameter in age group $\geq 40$ years.

Conclusion: Men had significantly larger arterial sizes than women in all of the intracranial arteries examined except right PCom, Left PCom and right MCA.

Keywords: Age, Circle of Willis, Sex.
\end{abstract}

\section{Introduction:}

Our brain needs a continuous perfusion. The circle of Willis (CoW) is the most important anastomosis between the internal carotid and vertebral system. It is the main distributor of blood to the brain. It is located at the base of the brain and allows equalization of blood- flow between the two sides of brain. It acts as a collateral pathway between the internal carotid artery and vertebral artery in case of reduced cerebral perfusion because of stenosis or occlusion of either of these vessels. Collateral potential of this circle of Willis, an arterial heptagon, is dependent on the presence and size of its component vessels. ${ }^{1,2}$ Current imaging techniques like computed tomography angiography , Magnetic resonance angiography and digital subtraction angiography helps in correct depiction of diameter of arteries forming circle of willis. ${ }^{3}$ The knowledge of the diameter of the circle of Willis have a greater importance in interventional radiology for various endovascular interventions and significant impact in collateral potential of circle of 
Willis. The present study analyses the transverse diameter of the arteries forming the circle of Willis in regards to gender and age.

\section{Methods:}

It was a cross sectional study conducted at the department of Radiology of Manipal Teaching Hospital between January 2019 and December 2020. Ethical clearance was obtained before the study. A random sampling of 220 Contrast enhancement Computed tomography (CT) of head with $1 \mathrm{~mm}$ thin section and 200 CT angiography of head was performed by Philips Ingenuity $128 \mathrm{CT}$ scanner. CT head and CT angiography were performed using standard scan parameters. Only the tests with normal radiological reports and appropriate technical standards were included in the study.

Patient with cerebral arteriovenous malformation, subarachnoid haemorrhage, surgical interventions in head, images with motion artifacts, brain tumors and incomplete Circle of Willis were excluded from the study. Component of circle of Willis: Anterior cerebral artery (ACA), Middle cerebral artery (MCA), Anterior communicating artery (Acom), Posterior Communicating artery (PCom), Basilar artery (BA) and Posterior cerebral artery (PCA) were identified. Transverse diameters of arteries were measured in axial plane. ACA, MCA and PCA were measured within 5 $\mathrm{mm}$ from their origin. Basilar artery was measured within $5 \mathrm{~mm}$ from bifurcation.

The tests were divided in groups based on patient's age ( $<40$ years and $\geq 40$ years) and gender (Male and Female). The differences in mean vessel diameters were correlated according to age and gender by $\mathrm{T}$ - test and $\mathrm{P}$ value. $\mathrm{P}$ value of $<0.05$ was considered as significant. Analysis was done using SPSS version 21.

\section{Results:}

Out of 420 Patient, 371 were excluded from the study and 49 were included for statistical analysis.

Forty-nine patients (21 males, 28 females) meeting the inclusion criteria were included for statistical analysis. The mean age of the patients was $51.8 \pm 19.5$ years Minimum age of the patient was 15 years and maximum age was 88 years.

Men had significantly larger arterial sizes than women in all of the intracranial arteries examined except right PCom, Left PCom and right MCA (Table 1).

Right ACA had significantly larger internal diameter in $<40$ years' age group. BA, left PCA, Bilateral PCom and MCA showed larger diameter in age group $\geq 40$ years, however it was not statistically significant. (Table 2)

Basilar artery was the artery with the largest internal diameter with mean diameter of $2.5 \pm 0.52 \mathrm{~mm}$. Mean internal diameter of right MCA and left MCA was 2.4 $\pm 0.52 \mathrm{~mm}$ and $2.4 \pm 0.49 \mathrm{~mm}$ respectively (Table 3 ).

\section{Discussion:}

The circle of Willis (CoW) connects the left internal carotid artery (ICA), right internal carotid artery and vertebrobasilar artery via communicating arteries. It is the main route for collateral blood flow in severe occlusive diseases of the internal carotid artery. Anatomical variations exist in over $50 \%$ of the population. ${ }^{4}$ Variations in the CoW are often caused by changes in the diameter. ${ }^{5}$

We observed that men had significantly larger arterial diameter of Right ACA, Left ACA, ACom, Left MCA, right PCA, Left PCA and BA than women. Shatri et al also observed that males had larger arterial diameter except for PCoA, which tended to be larger in females. ${ }^{6}$ In our case, right PCom was larger in males which was 
not significant and diameter of left PCom was equal in males and females.

In our study, basilar artery was the largest artery by diameter which correlated with findings of other studies. ${ }^{3,7,8,9}$ While comparing the arterial diameter across the two age groups, the diameter of the basilar artery in our study was slightly larger in patients $\geq 40$ years old. Stefani et al. also found significantly larger diameters of the BA in individuals older than 40 years. ${ }^{7}$ Shatri et al and Maaly and colleagues revealed the contradictory finding that the subjects older than 40 years had significantly smaller diameter of BA.,8 Mujagic et al confirmed that males had significantly larger basilar artery similar to our finding. ${ }^{3}$ But Chen et al also observed that basilar artery was larger in females. ${ }^{9}$ ACA is one of the largest ending branches of ICA that supplies the medial surface of the cerebral hemisphere. We observed that right ACA diameter was wider among less than 40 years' age group patients contradicting to the finding of other authors who observed larger diameter in more than 40 years' age group. ${ }^{6}$ Chen et al found that older patients had smaller caliber in the left ACA than the younger patients. ${ }^{9}$ Maaly and colleague showed significantly smaller diameter of ACA in older age group's patients. ${ }^{8}$ Mujagic S and Shatri et al observed that ACA diameter was significantly larger in males. ${ }^{3,6}$ Hafez et al also observed the diameter to be larger in males. ${ }^{10}$ The diameter of left and right ACA were significantly larger in males in our study.

Shatri et al observed that MCA and PCA diameter was significantly larger in individuals more than 40 years of age. ${ }^{6}$ We also found that MCA and left PCA were larger in internal diameter in $\geq 40$ years' age group. But the diameter of Right PCA was larger in less than 40 years' age group. Both right and left MCA were significantly larger in males in our study.
Regarding PCA in our study, both right PCA and left PCA was significantly larger in males. Right PCA was larger than the left PCA in males but right PCA diameter equaled to left PCA diameter in females. Mujagic et al confirmed that left PCA was significantly larger than the right PCA in females, while in males the diameters of the right and left PCA were equal. ${ }^{3}$ Several studies have observed the PCA artery to be larger in males. ${ }^{7,8,10,11}$ Chen et al observed that females had larger PCA as compared to males but the finding was not significant. ${ }^{9}$

We observed that both right and left PCom was smaller in diameter in patients younger than 40 years' age group but Maaly and colleague observed significantly smaller diameter of PCOA in subjects older than 40 years. ${ }^{8}$ Several studies have confirmed the PCom to be larger in females. ${ }^{3,7,8,10,11}$

Our study did not correlate well with the findings of other studies. This may be due to the geographic, ethnic or racial differences. We could not consistently prove that the arteries of $\mathrm{CoW}$ were either smaller or larger in younger or older age groups, we got variable result. This may be due to smaller sample size in our study. We just correlated vessel's diameter with age and sex. We did not assess other parameters of the vessels of Circle of Willis.

Conclusions: Males had significantly larger arterial sizes than women in all of the intracranial arteries examined except right PCom, Left PCom and right MCA. Right ACA had significantly larger internal diameter in less than 40 years' age group. BA, left PCA, Bilateral PCom and MCA showed larger diameter in age group $\geq 40$ years. Further research with larger sample size is indicated to validate our finding. 
Table 1: The diameters of arteries forming Circle of Willis and statistical significance between male and female

\begin{tabular}{|c|c|c|c|c|c|}
\hline \multicolumn{3}{|l|}{ Male $(n=21)$} & \multicolumn{3}{|l|}{ Female $(n=28)$} \\
\hline Arteries & $\begin{array}{l}\text { Mean internal } \\
\text { diameter }(\mathrm{mm})\end{array}$ & SD & $\begin{array}{l}\text { Mean internal } \\
\text { diameter }(\mathrm{mm})\end{array}$ & SD & $P$ - value \\
\hline Right ACA & 1.9 & 0.48 & 1.6 & 0.27 & 0.011 \\
\hline Left ACA & 2.1 & 0.41 & 1.8 & 0.40 & 0.016 \\
\hline Acom & 1.57 & 0.50 & 1.2 & 0.30 & 0.011 \\
\hline Right MCA & 2.5 & 0.53 & 2.3 & 0.50 & 0.103 \\
\hline Left MCA & 2.6 & 0.34 & 2.2 & 0.52 & 0.003 \\
\hline Right Pcom & 1.4 & 0.51 & 1.3 & 0.30 & 0.65 \\
\hline Left Pcom & 1.3 & 0.44 & 1.3 & 0.33 & 0.88 \\
\hline Right PCA & 2.0 & 0.37 & 1.6 & 0.36 & 0.001 \\
\hline Left PCA & 1.9 & 0.41 & 1.6 & 0.34 & 0.028 \\
\hline BA & 2.7 & 0.49 & 2.3 & 0.49 & 0.010 \\
\hline
\end{tabular}

ACA: Anterior Cerebral Artery; Acom: Anterior Communicating MCA: Middle Cerebral Artery; Pcom:

Posterior Communicating; PCA: Posterior Cerebral Artery; BA: Basilar Artery

\begin{tabular}{|c|c|c|c|c|c|}
\hline \multicolumn{3}{|c|}{$<40$ Years of Age $(n=17)$} & \multicolumn{3}{|c|}{$\geq 40$ Years of Age $(n=32)$} \\
\hline Arteries & $\begin{array}{l}\text { Mean internal } \\
\text { diameter }(\mathrm{mm})\end{array}$ & $\mathrm{SD}$ & $\begin{array}{l}\text { Mean internal } \\
\text { diameter }(\mathrm{mm})\end{array}$ & SD & P- Value \\
\hline Right ACA & 1.9 & 0.43 & 1.7 & 0.36 & 0.04 \\
\hline Left ACA & 1.9 & 0.46 & 1.9 & 0.41 & 0.66 \\
\hline Acom & 1.4 & 0.35 & 1.3 & 0.45 & 0.25 \\
\hline Right MCA & 2.2 & 0.47 & 2.5 & 0.09 & 0.39 \\
\hline Left MCA & 2.3 & 0.45 & 2.4 & 0.51 & 0.33 \\
\hline Right Pcom & 1.3 & 0.32 & 1.4 & 0.44 & 0.78 \\
\hline Left Pcom & 1.2 & 0.35 & 1.3 & 0.39 & 0.19 \\
\hline Right PCA & 1.8 & 0.38 & 1.7 & 0.42 & 0.41 \\
\hline Left PCA & 1.7 & 0.38 & 1.8 & 0.40 & 0.74 \\
\hline BA & 2.4 & 0.42 & 2.5 & 0.57 & 0.64 \\
\hline
\end{tabular}




\begin{tabular}{lcc}
\hline \multicolumn{2}{l}{ Table 3: Mean internal diameter of arteries forming Circle of Willis irrespective of age and sex. } \\
\hline Arteries & Internal diameter $(\mathrm{mm})$ & $\mathrm{SD}$ \\
Right ACA & 1.8 & 0.40 \\
Left ACA & 1.9 & 0.42 \\
Acom & 1.3 & 0,42 \\
Right MCA & 2.4 & 0.52 \\
Left MCA & 2.4 & 0.49 \\
Right Pcom & 1.3 & 0.40 \\
Left Pcom & 1.3 & 0.38 \\
Right PCA & 1.8 & 0.41 \\
Left PCA & 1.8 & 0.39 \\
BA & 2.5 & 0.52 \\
\hline
\end{tabular}

\section{Reference:}

1. Lo WB, Ellis H. The circle before willis: a historical account of intracranial anastomosiss. Neurosurgery. 2010;66:7-18.

\section{https://doi.org/10.1227/01.NEU.0000362002.63241.A}

2. Symonds C. The circle of Willis. Br Med J. 1955;1:119. https://doi.org/10.1136/bmj.1.4906.119.

3. Mujagic S, Moranjkic M, Mesanovvic N, Osmanovic S. The inner diameter of arteries of the circle of willis regarding gender and age on Magnetic resonance angiography. Acta Medica Saliniana Tuzla. 2013;44(2):6-12.

4. Flaherty ML, Woo D, Haverbusch M, Sekar P, Khoury J, Sauerbeck L, et al. Racial variations in location and risk of intracerebral hemorrhage. Stroke. 2005; 36(5):934-93. https://doi.org/10.1161/01.STR.0000160756.72109.9

5. Alpers BJ, Berry RG, Paddison RM. Anatomical studies of the circle of Willis in normal brain. AMA Arch Neurol Psychiatry. $\quad 1959 ; \quad 81(4): 409-18$. https://doi.org/10.1001/archneurpsyc.1959.0234016000 $\underline{7002}$.

6. Shatri J, Bexheti D, Bexheti S, Kabashi S, Krasniqi S, Ahmetgjekaj I, et al. Influence of Gender and Age on Average Dimensions of Arteries Forming the Circle of Willis Study by Magnetic Resonance Angiography on
Kosovo's Population. Maced J Med Sci. 2017;5(6):714719. https://doi.org/10.3889/oamjms.2017.160.

7. Stefani MA, Schneider FL, Marrone ACH, Severino AG. Influence of the gender on cerebral vascular diameters observed during the magnetic resonance angiographic examination of willis circle. Braz. arch. biol. technol. 2013; 56(1);45-52. https://doi.org/10.1590/S1516$\underline{89132013000100006 .}$

8. Maaly MA, Ismail AA. Three dimensional magnetic resonance angiography of the circle of Willis: Anatomical variations in general Egyptian population. The Egyptian Journal of Radiology and Nuclear Medicine.

2011;42:405-12. https://doi.org/10.1016/j.ejrnm.2011.09.001

9. Chen HW, Yen PS, Lee CC, Chen CC, Chang PY, Lee SK et al. Magnetic resonance angiographic evaluation of circle of Willis in general population: a morphologic study in 507 cases. Chin J Radiol. 2004;29(5):223-29.

10. Hafez KA, Afifi NM, Saudi FZ. Anatomical Variations of the Circle of Willis in Males and Females on 3D MR Angiograms. The Egyptian Journal of Hospital Medicine 2007;26:106-21. https://doi.org/10.21608/ejhm.2007.17785.

11. Voljevica A, Talovic E, Pepic E, Kapic AP. Morphometric analysis of Willis circle arteries. Arch Pharm Pract $\quad \underline{\text { htps://doi.org/10.4103/2045- }}$ 080X.112988. 